\title{
UnEXPECTED FInding DURING BREAST CANCER StAGING
}

ana Patrícia Vicente ${ }^{1}$, Catarina Gama Pinto ${ }^{1}$, lídia Reis ${ }^{1}$, Filomena Nunes ${ }^{1}$, Isabel Serrano ${ }^{2}$, Paulo Mira ${ }^{3}$, Francisco Guerra Pinto ${ }^{4}$, Emanuel Gonçalves ${ }^{5}$, Ana Sofia Moreira ${ }^{6}$, Frederik A.A. JONGE ${ }^{7}$,Teresa C. Ferreira ${ }^{7}$

${ }^{1}$ Department of Obstetrics and Gynecology, Hospital de Cascais Dr. Jose de Almeida 2Department of Pathological Anatomy, Hospital de Cascais Dr. Jose de Almeida ${ }^{3}$ Defartment of General Surgery, Hospital de Cascais Dr. Jose de Almeida ${ }^{4}$ Department of Orthopaedics, Hospital de Cascais Dr. Jose de Almeida ${ }^{5}$ Department of OnCOlogy, Hospital de CASCAIS Dr. Jose de Almeida ${ }^{6}$ Department of Radiology, Hospital de Cascais Dr. Jose de Almeida 7 Department of Nuclear Medicine, Hospital dos lusiadas

INTRODUCTION

LISBON, PORTUGAL

Breast cancer is the most frequent malignancy diagnosed in females. After diagnosis, staging is essential to determine the extent of the disease and adjust the therapeutic approach. Unexpected findings can appear during staging. In patients with breast cancer, the incidence of multiple primaries has been reported in the range of 4,1 to $16,4 \%$.

\section{CASE REPORT}

We present a case of hematologic cancer, diagnosed incidentally during the staging of breast carcinoma.

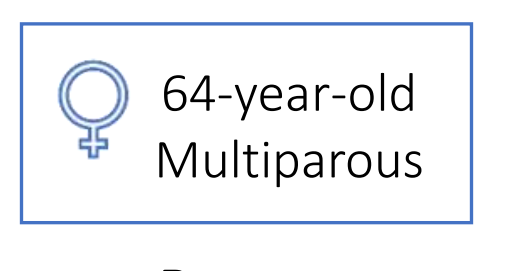

\section{ROUTINE}

Mammogram

RB BIRADS 4/5

Supra areolar nodule, heterogeneous and poorly defined, with approximately $20 \mathrm{~mm}$

No suspicious axillary nodes
GUIDED

GLTRASOUND
BIOPSY

INVASIVE

\section{DUCTAL BREAST} CARCINOMA

ER e PR $40 \%$ HER2 +

Ki67 30\%
Grade 1,<smiles>C1C2C3C4C1C1C2C3C41</smiles>

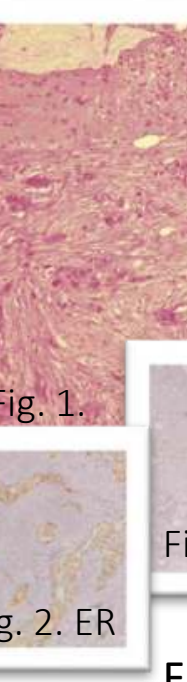

Figure (Fig.) 1, 2, 3, 4. Fig. 1. H\&E 100x; Fig. 2, 3, 4 Immunohistochemistry analysis

\section{StAging \\ BREAST MRI \\ “(...) spiculated mass, $20 \mathrm{~mm}$ in diameter, with minor nipple- areolar complex retraction (...)"

x

ThORACo
AbDominal CT
“(..) abdominal
cystic 50 mm mass
$\left({ }^{*}\right)$, with thin walls,
contiguous to the
anterior portion of
the aortic
bifurcation (...)"

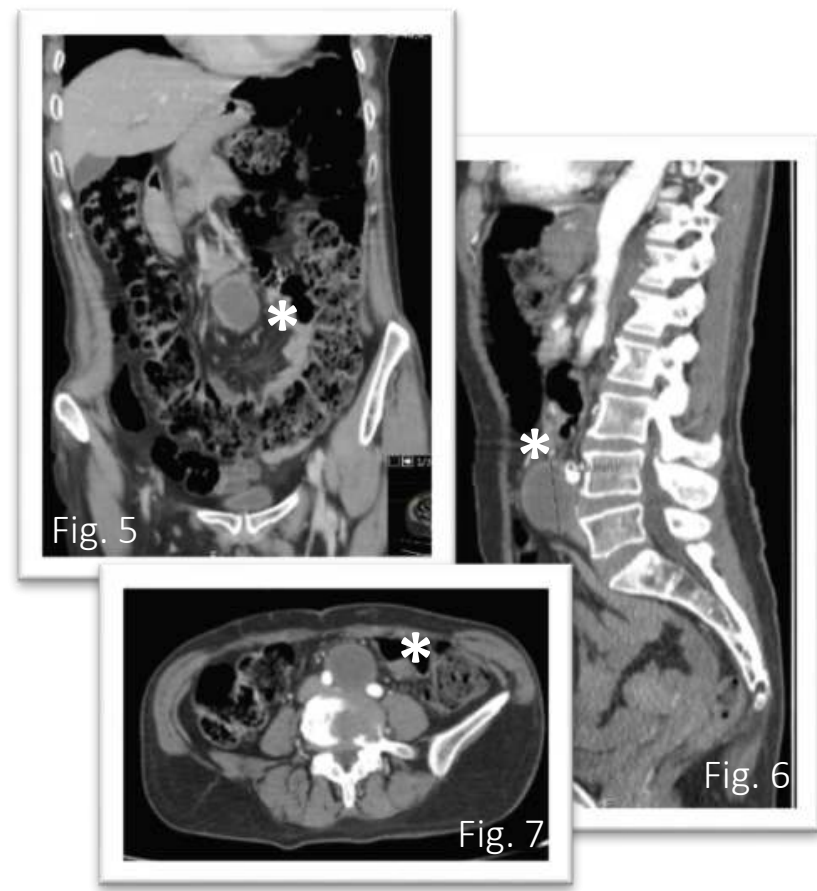

Fig. 5, 6, 7. Thoracoabdominal CT: Coronal, sagittal and axial view.

\section{BONE SCINTIGRAPHY \\ Minimal abnormal uptake in the right radius and right femur Extensive diaphyseal uptake in the left tibia}

$\begin{array}{cc}\text { Pelvic MRI } & \text { PET-CT } \\ \text { Suspicious } & \text { Metabolically active } \\ \text { nodular lombo } & \text { abdominal lesion and } \\ \text { aortic mass, with } & \text { medullary infiltration } \\ \text { cystic / necrotic } & \text { of the left tibia }\end{array}$
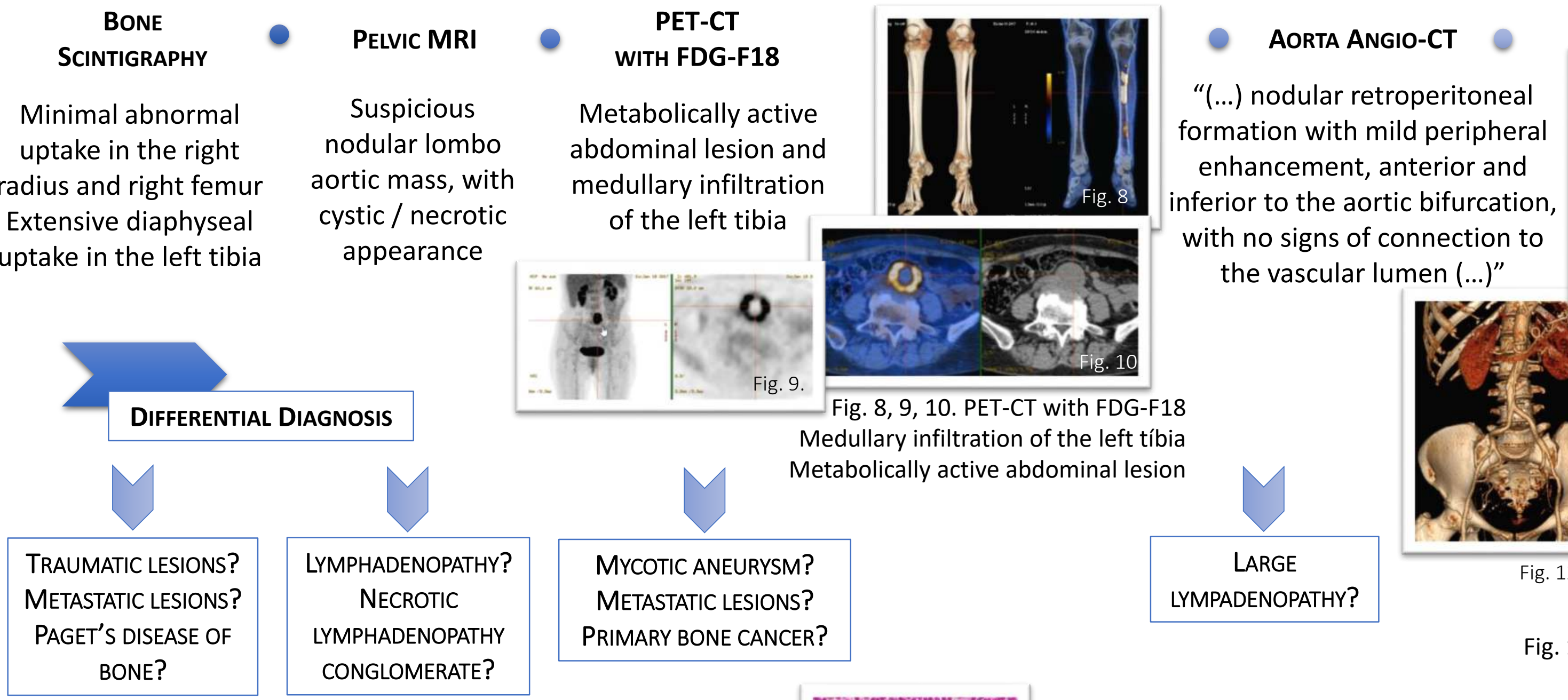
appearance
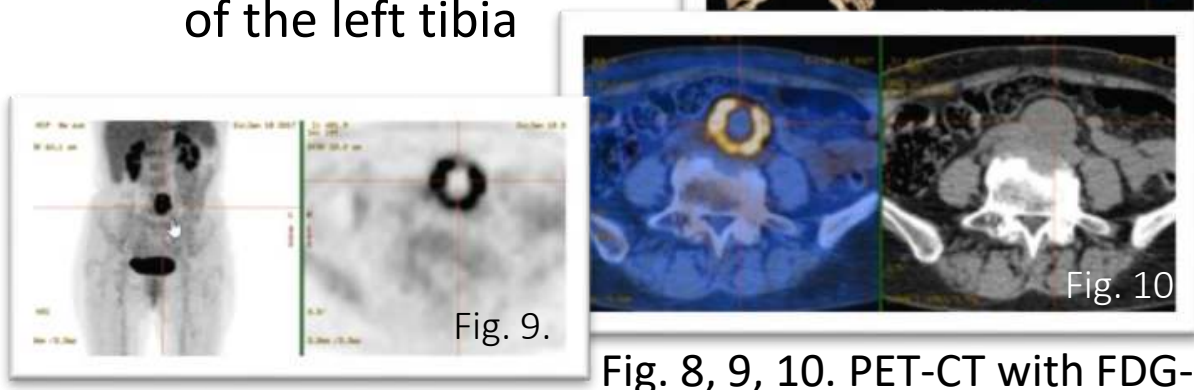

Fig. 8, 9, 10. PET-CT with FDG-F18 Medullary infiltration of the left tíbia Metabolically active abdominal lesion
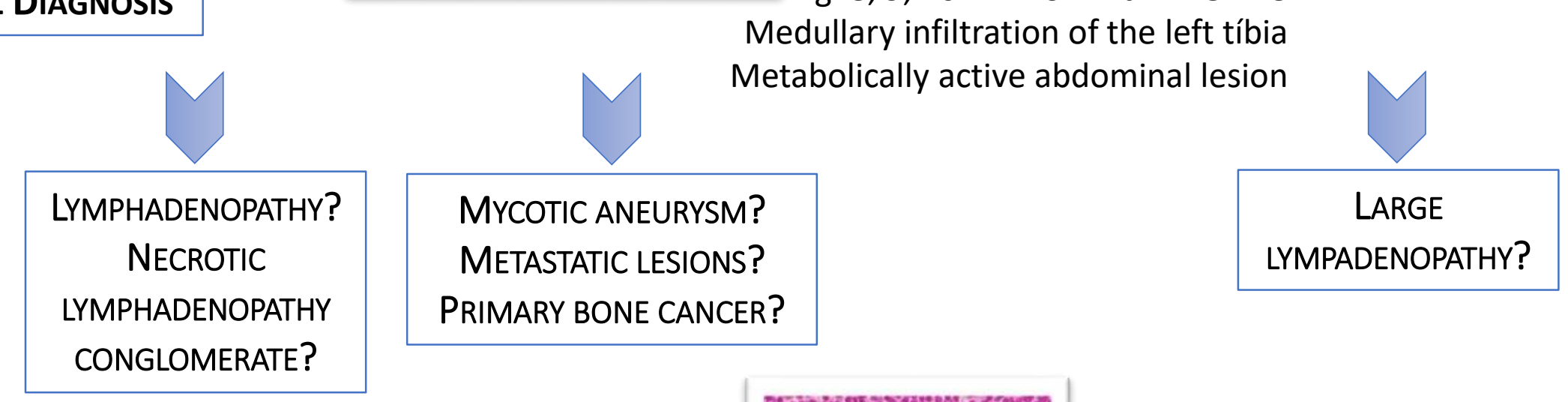

PRIMARY BONE CANCER?

\section{Diagnostic LAPAROTOMY}

$\checkmark$ Abdominal mass biopsy TIBIAL BIOPSY

DIFFUSE FOLLICULAR NON-HODGKIN B CELL LYMPHOMA, GRADE 3A

Fig. 14 to 20 . Pathological examination Fig. 14, 15. H\&E 40x e 400x Bone biopsy Fig, 16. H\&E 40x Abdominal mass biopsy Fig. 17 to 20 Immunohistochemistry analysis

\section{CONCLUSION}

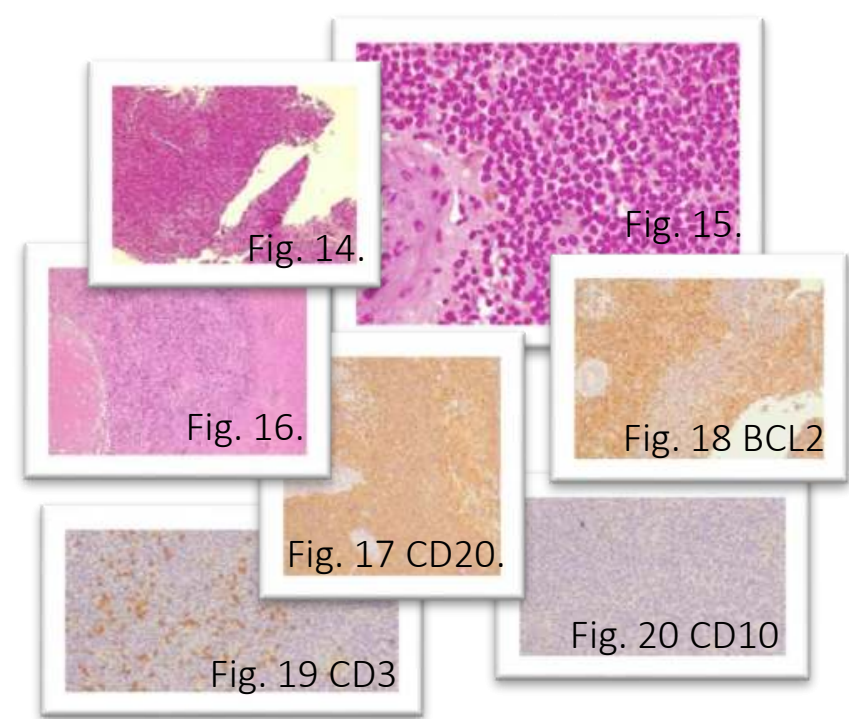

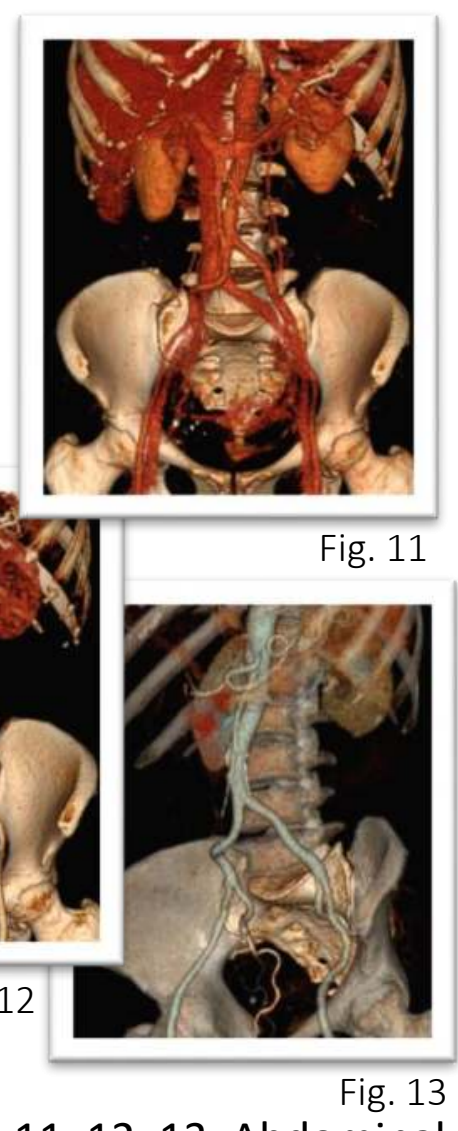

Fig. 11, 12, 13. Abdominal Aorta Angio-CT \section{with sentinel lymph node biopsy \\ Chemotherapy Biological therapy (R-CHOP) Radiotherapy
Hormonotherapy} pT2 pN1 (1/4) MO Grade 2 ER $40 \%$ PR 5-10\% HER2 + Ki67 30\%
THERAPEUTIC APPROACH

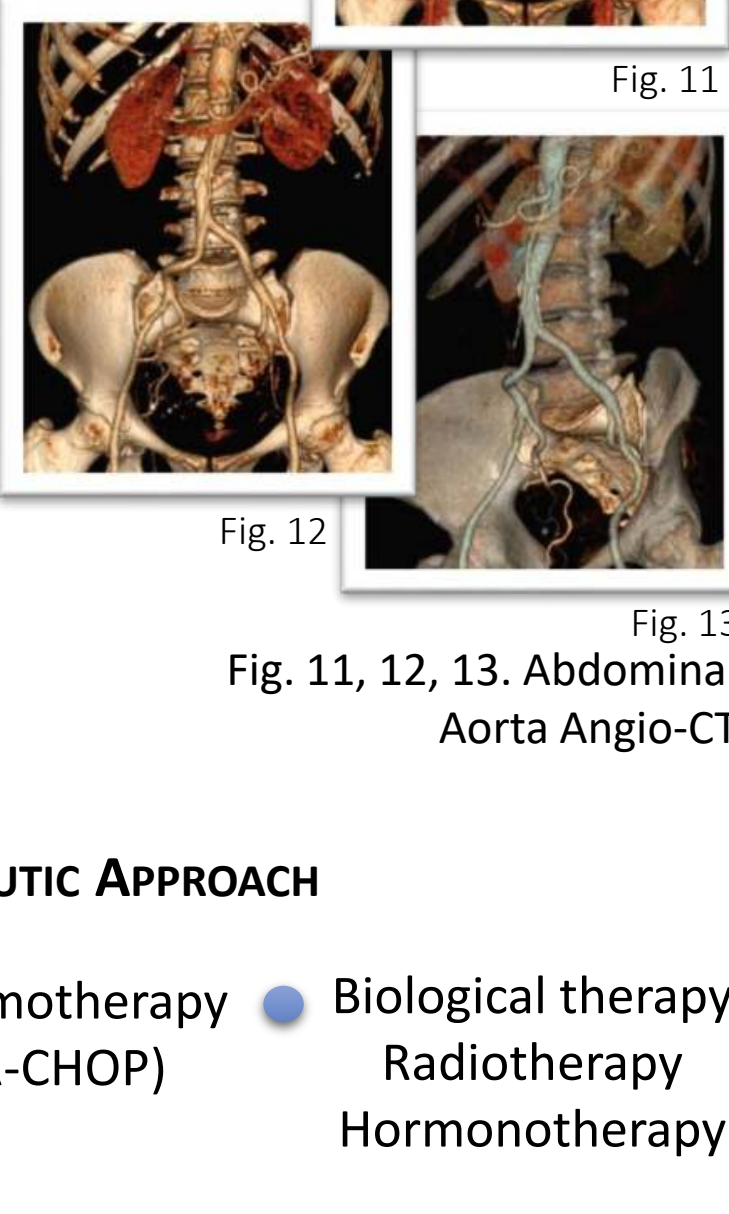

In rare occasions new and unexpected findings may appear when staging a malignancy. Besides metastases, we must remember and consider less frequent breast cancers and also the rare possibility of two coexistent yet different malignancies. Careful investigation and a multidisciplinary approach of the patient is mandatory.

REFERENCES

Vogt A, Schmid S, Heinimann K, et al. Multiple primary tumours: challenges and approaches, a review. ESMO Open 2017;2:e000172.

Siegel RL, Miller KD, Jemal A. Cancer Statistics, 2017. CA Cancer J Clin 2017; 67:7

Papajík T, et al. Synchronous second primary neoplasms detected by initial staging F-18 FDG PET/CT examination in patients with non-Hodgkin lymphoma. Clin Nucl Med. 2011 Jul;36(7):509-12

Cuff KE, et al. Synchronous breast cancer and lymphoma: a case series and a review of the literature. J Clin Pathol. 2010 Jun;63(6):555-7

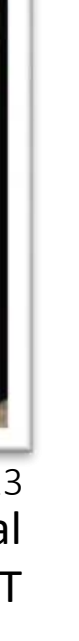

(1)

